\title{
THE EXPANSION OF THE PORT OF HANSTHOLM - THE FUTURE CONDITIONS FOR A BYPASS HARBOUR
}

\author{
Bo Brahtz Christensen ${ }^{1}$, Rolf Deigaard ${ }^{1}$, Ida Brøker ${ }^{1}$, Kasper Kærgaard ${ }^{1}$, Asger Bendix \\ Hansen $^{1}$, Nils Drønen ${ }^{1}$, Anders Helkjær ${ }^{2}$ and Helge Gravesen ${ }^{2}$
}

\begin{abstract}
As part of the investigations for a major expansion of the Port of Hanstholm a series of hydraulic studies were carried out involving: field measurements of waves and currents, establishment of design conditions for waves and currents, analysis of the wave disturbance, laboratory tests of breakwater stability, analysis of the future conditions for sediment bypass and sedimentation and possible impact on the surrounding coastlines. In this paper the extensive sediment studies made by application of numerical modelling is described.
\end{abstract}

Keywords: Port of Hanstholm; sediment bypass; sedimentation; littoral drift; coastal impact

\section{INTRODUCTION}

The Port of Hanstholm is a major Danish fishery and freight port located at the Danish West Coast facing the North Sea. It is an outstanding example of a bypass harbour. Since its construction in the 1960 -ies only a small fraction of the littoral drift of $500,000 \mathrm{~m}^{3}$ that annually passes the harbour has to be dredged to maintain the required navigation depth (Sørensen et al., 1996).

\section{History}

The harbour is placed at a headland at a location fully exposed to North Sea waves coming from westerly and northwesterly directions, Fig. 1. The location was chosen based on the idea that in order to reduce sedimentation problems harbours on the North Sea coast should be built at exposed promontories rather than in bays. This 'point theory' was introduced by engineer Jørgen Fibiger in the beginning of the $20^{\text {th }}$ century based on theories by the Italian engineer Paolo Cornaglia.

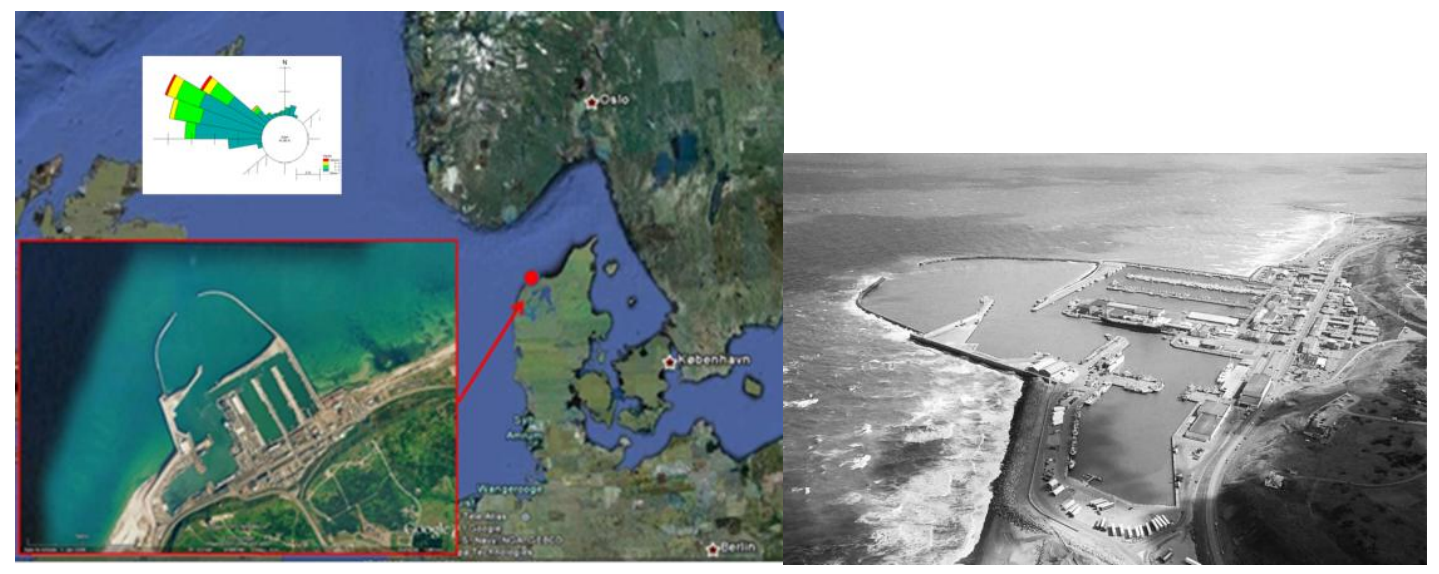

Figure 1. Hanstholm Harbour at the Danish North Sea coast.

The construction works were initiated in 1919 but progressed very slowly, and when the site was evacuated in 1941 only the western breakwater was near completion. The breakwater fell into disrepair. A technical commission reviewed the project in 1951 and found it to be infeasible due to sedimentation problems. However, local representatives in the commission found that it was plausible that the massive accumulation of sand found in the lee of the breakwater would not have occurred if the eastern breakwater had been in place to promote the natural bypass of sand past the harbour mouth.

At the initiative of professor Lundgren the technical aspects of the project were re-examined at the Technical University of Denmark. The work included field measurements, development of new theories and laboratory experiments. In a new commission report of 1959 it was concluded that the project was basically sound, and the construction work was started with the use of concrete (instead of

\footnotetext{
${ }^{1}$ DHI, Agern Allé 5, 2970 Horsholm, Denmark

${ }^{2}$ Grontmij A/S, Granskoven 8, 2600 Glostrup, Denmark
} 
the original wooden) caissons and a revised shape of the breakwaters optimised to promote the bypass of sand.

\section{Existing conditions}

There is a north-going littoral transport along the coast south of Hanstholm. The transport rate has been estimated from the recorded coastline erosion, and different estimates have been in the interval $400-700,000 \mathrm{~m}^{3} / \mathrm{yr}$, with the latest estimate of $400,000 \mathrm{~m}^{3} / \mathrm{yr}$ by the Danish Coastal Authority (2001). The present study has used an estimate of approximately $500,000 \mathrm{~m}^{3} / \mathrm{yr}$.

The sand is passing the harbour mouth and a navigation depth of about $8 \mathrm{~m}$ or more is maintained with an annual dredging volume from the outer harbour and in front of the entrance of 50-100,000 $\mathrm{m}^{3} / \mathrm{yr}$. The present harbour is therefore a success with an annual maintenance dredging corresponding to a small fraction of the sand that passes in front of the harbour entrance. The sand passes the harbour during northwesterly storm conditions under the combined action of the waves and the west-going current, which is driven by wind and waves. The sand is transported within a zone of 100-300 m width in front of the harbour. The high transport capacity at such large water depth is to a large degree facilitated by the design of the harbour, which increases the high current velocities already caused by contraction of the current passing the headland at Hanstholm. The low sedimentation rate is further due to the presence of the lee breakwater, which prevents the sand from being brought into the harbour by a lee vortex and by the rather narrow harbour mouth of $130 \mathrm{~m}$ width (Brøker et al. 2007). The favourable sediment conditions have in part been at the expense of the navigation conditions during rough weather due to the shear in the current in front of the rather narrow harbour mouth.

It should be noted that it is not the same conditions that dominate the north-going transport on the coast south of the harbour and drive the sand bypass past the harbour. This means that the accumulation of sand in front of and southwest of the harbour is variable, and that the navigation depth in the approach to the harbour may vary.

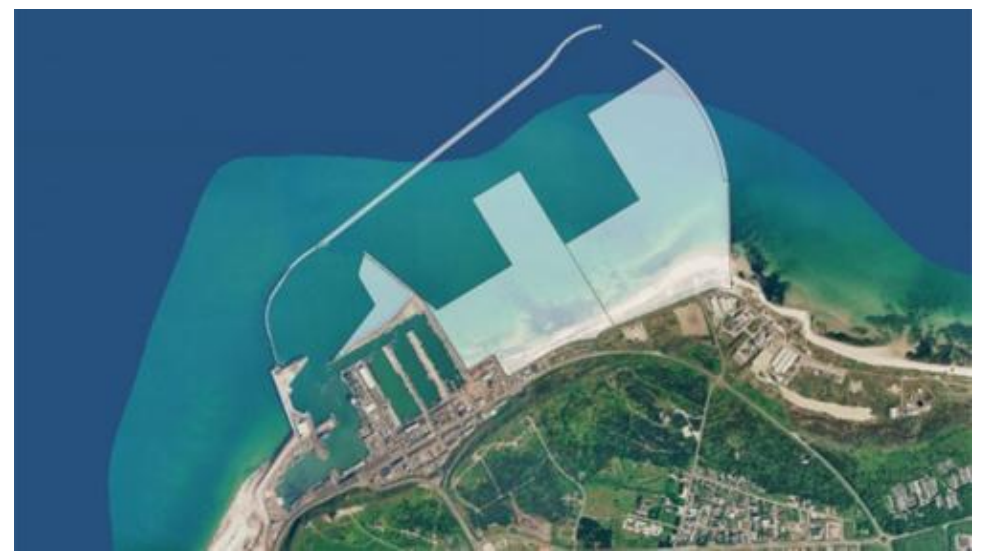

Figure 2. Planned extension of the Port of Hanstholm. The existing harbour forms the east part of the future harbour.

\section{Planned expansion of the harbour}

The Port of Hanstholm plans a major extension. A preliminary layout of the new facilities is shown in Fig. 2. The main characteristics are: The expanded harbour is several times larger than the existing; the new entrance is placed northeast of the present, which is to be closed; the water depth in the entrance and approach to the harbour is to be maintained at $12.5 \mathrm{~m}$. In the layout of the new harbour, in particular the location and orientation of the entrance, priority has been given to the future navigation conditions.

In connection with the expansion there are a number of questions related to the sand transport that have been addressed. The main questions are: how are the future conditions for bypass of sand past the harbour and how much dredging is expected to be necessary to maintain the $12.5 \mathrm{~m}$ navigation depth? How are the conditions for deposition of sand along the new main northern breakwater west of the entrance? What is the impact on the surrounding coastlines if the conditions for bypass are changed? 


\section{SEDIMENT CONDITIONS AROUND THE FUTURE HARBOUR}

The future sediment transport condition have been investigated by application of the numerical model system MIKE21, using the flexible mesh modules for wave transformation, currents, sediment transport and morphological evolution. Local models have been established to describe the present and future conditions, while regional wave and current models covering the entire North Sea and parts of the inner Danish waters are used to establish boundary conditions and to select the periods and events to be simulated by the detailed models, Fig. 3 .
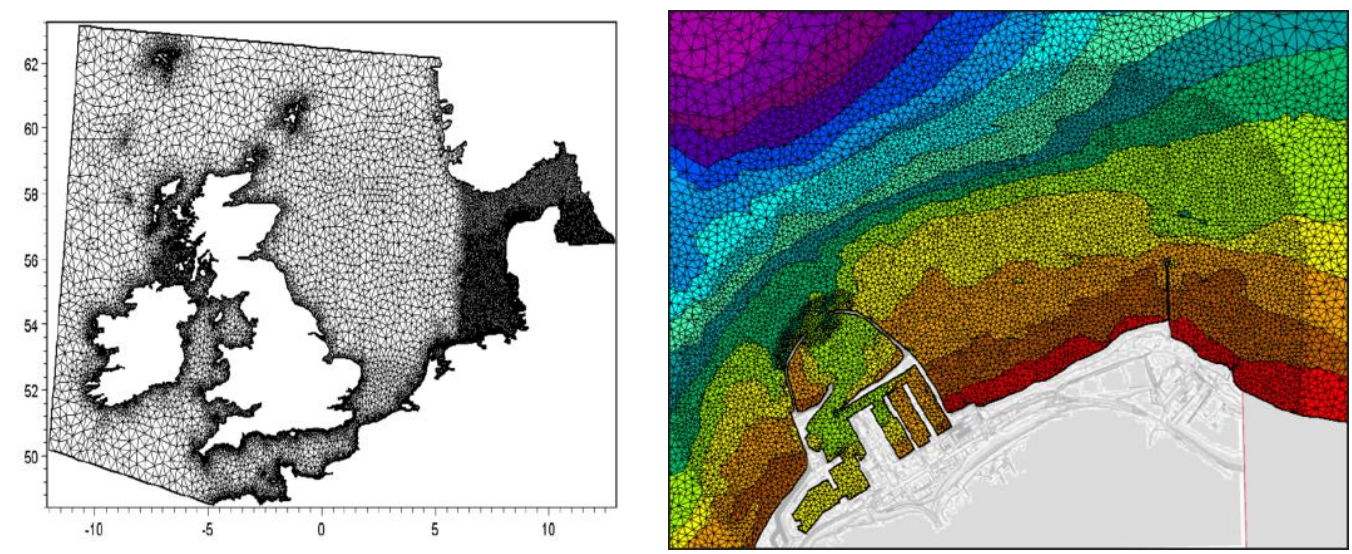

Figure 3. Left: the regional model. Right: The local model, detail of grid around the existing harbour.

The models were calibrated against wave- and current measurements taken at positions $1 / 2-1 \mathrm{~km}$ northwest of the present harbour. The field data comprise current profiles and wave measurements in the period January-May 2011 made by DHI by use of a TRIAXYS buoy system with ADCP and a long time series of wave measurements by the Danish Coastal Authority. On the night between May 10 and 11 the current field was measured under a situation with east-going current. The measurements were made by an ADCP instrument mounted on a boat that sailed in a number of transects. Fig. 4 shows the measured current field together with a current field simulated by the local flow model for similar flow conditions.

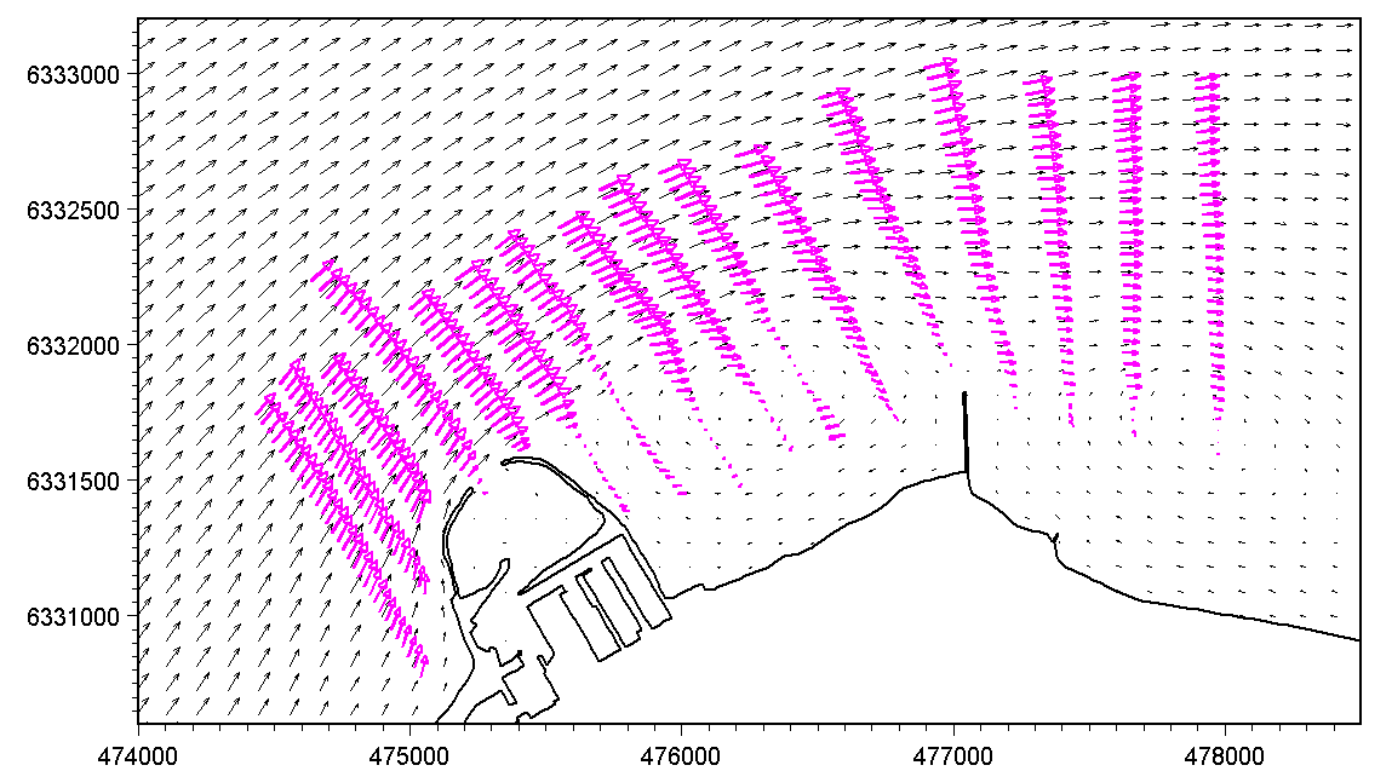

Figure 4. Measured current transects (purple) and simulated current pattern.

Simulations of the wave-, current and sediment transport over the present bathymetry conditions during a series of storms showed that the sediment transport capacity past the future harbour mouth was significantly lower than for the present harbour layout, this is partly because the extended harbour 
causes less contraction of the current but is primarily due to the larger water depth in the harbour mouth and in front of the harbour, Fig. 5.
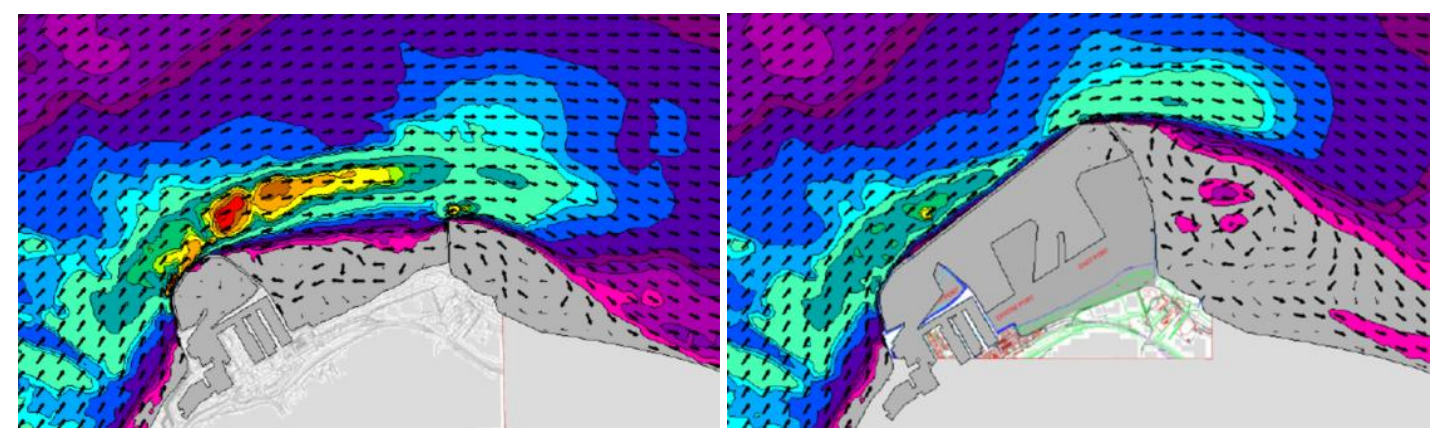

Figure 5. Sediment transport intensity under an extreme storm, January 2005. Left: Existing conditions. Right: The future harbour.

These simulations demonstrated that it will not be possible to maintain a navigation depth of 12.5 $\mathrm{m}$ without a significant maintenance dredging. A number of modifications of the layout around the harbour mouth were tested, and it was found that any improvements that could be obtained were not substantial enough to allow for an increase in the construction costs. The situation with a gently curved northern breakwater has also been investigated without finding that the bypass conditions were improved.

The sedimentation conditions for the future harbour were investigated by a series of simulations by the MIKE21 model. It was obvious that the rather low transport capacity along the new main northern breakwater would give rise to sedimentation here. The deposition has been analysed by simulation of a number of configurations. It was first assumed that the deposit would have the form of a constant slope of 1:40 normal to the breakwater, and the shape of the deposit is therefore defined by the variation of the bed level along the breakwater, Fig. 6. An equilibrium configuration was determined by iteration fulfilling the requirement that the transport along the main northern breakwater should be approximately uniform under NW storm conditions and that the transport capacity should be approximately $500,000 \mathrm{~m}^{3}$ for a typical year, Fig. 7 .
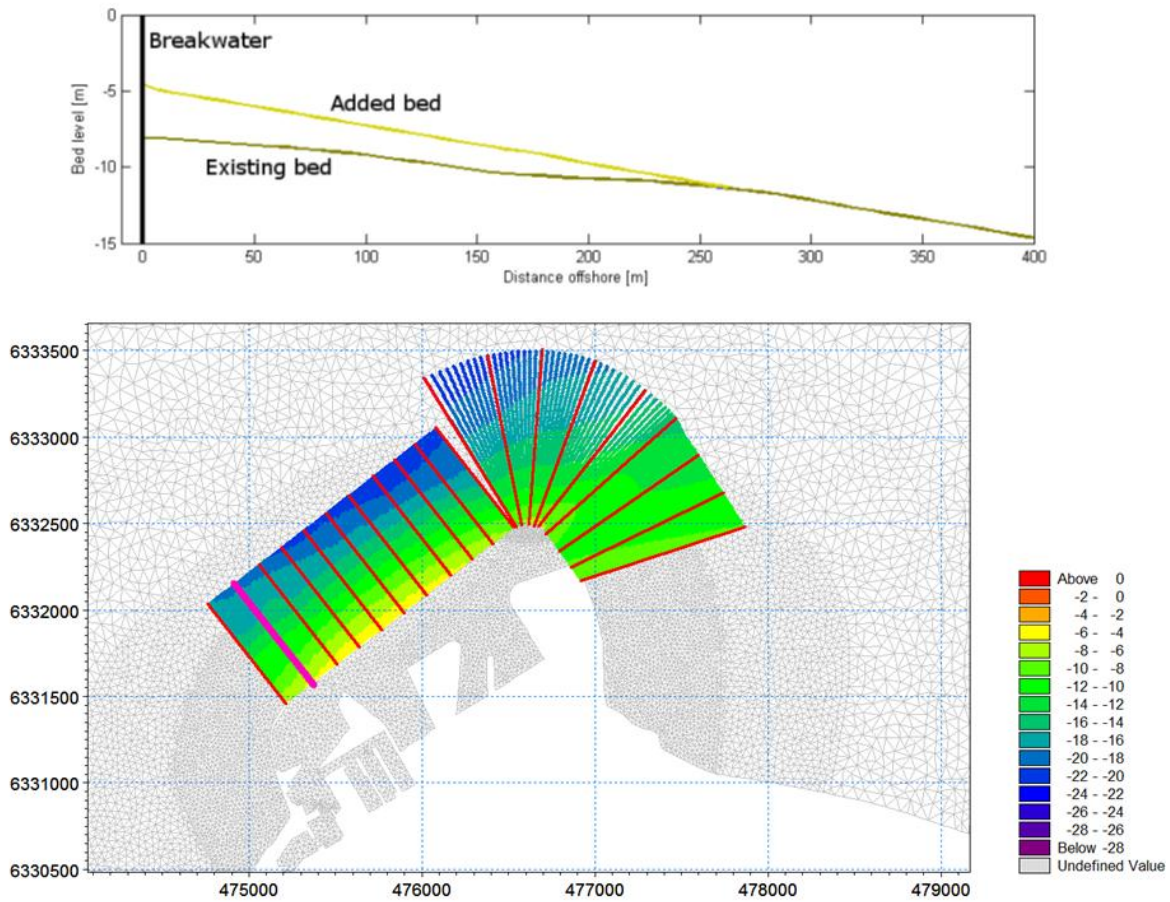

Figure 6. Top: Deposition in front of the breakwater is described with a constant bed slope. Bottom: The deposition is specified by the bed level at the breakwater in a number of cross-sections. 

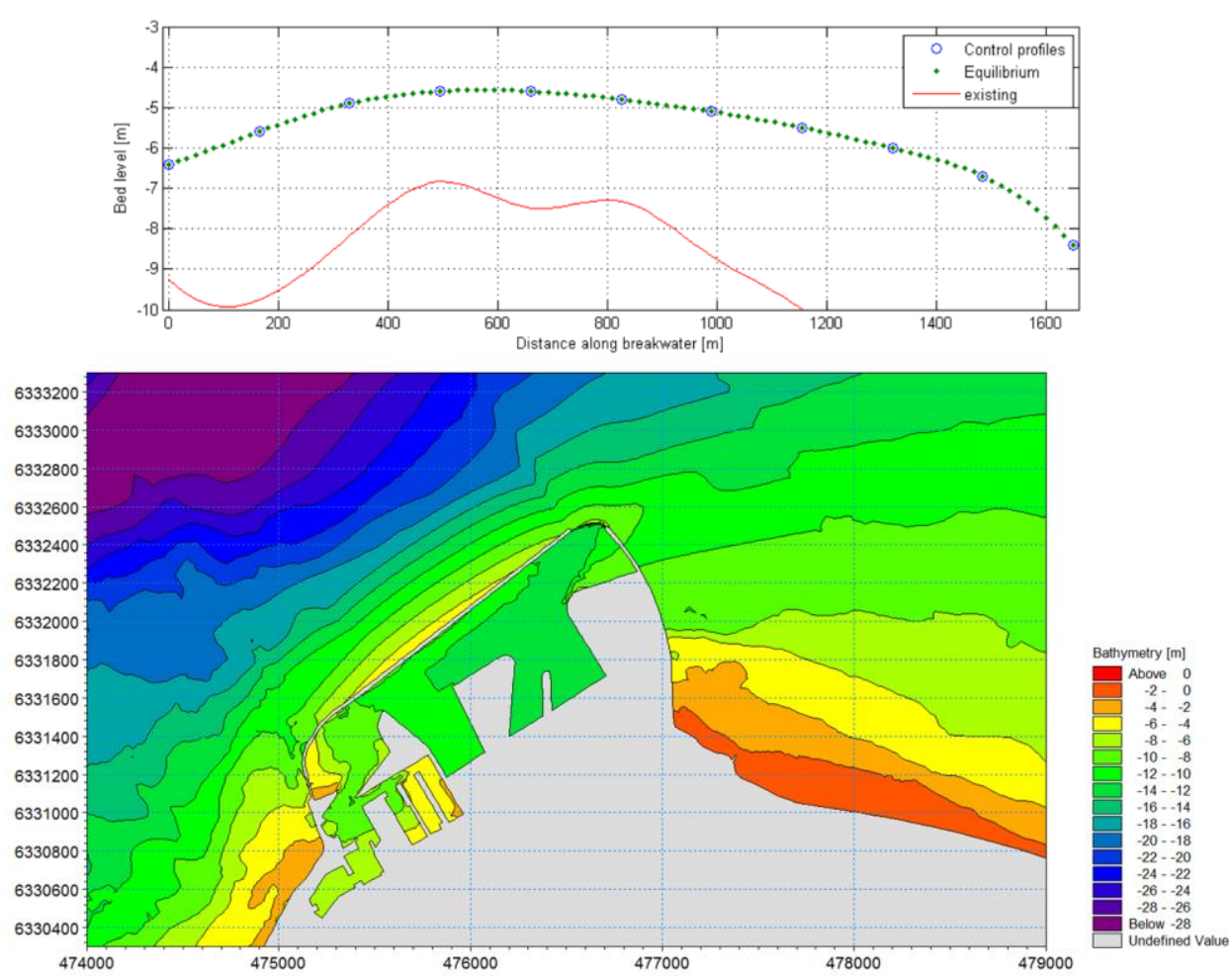

Figure 7. Deposition corresponding to an equilibrium. Top: Bed level along the main northern breakwater (red curve: original bed level). Bottom: The bathymetry, the depth in front of the harbour entrance is 8-9 $\mathrm{m}$.

The sensitivity to the assumed bed slope in front of the main northern breakwater was investigated by simulations with a gentler slope; it was found that the results were qualitatively similar and that the water depths at the harbour mouth were approximately the same. A simulation where it was assumed that the deposit along the breakwater was in shape of a bar was also carried out giving similar results with respect to the water depth at the harbour entrance.

For comparison of methods supplementary investigations were conducted by use of a dynamic research simulation model using the hybrid model concept (Kristensen et al. 2010 and 2013). The model simulates the morphological evolution with constraints on the bed evolution: morphological evolution is only simulated in the depositional area in front of the main northern breakwater and the deposition is with a fixed slope. The hybrid model showed a dynamic behaviour with sand formations propagating along the breakwater until the sedimentation takes place. Fig. 8 shows an example of the instantaneous bed configuration during the evolving deposition.

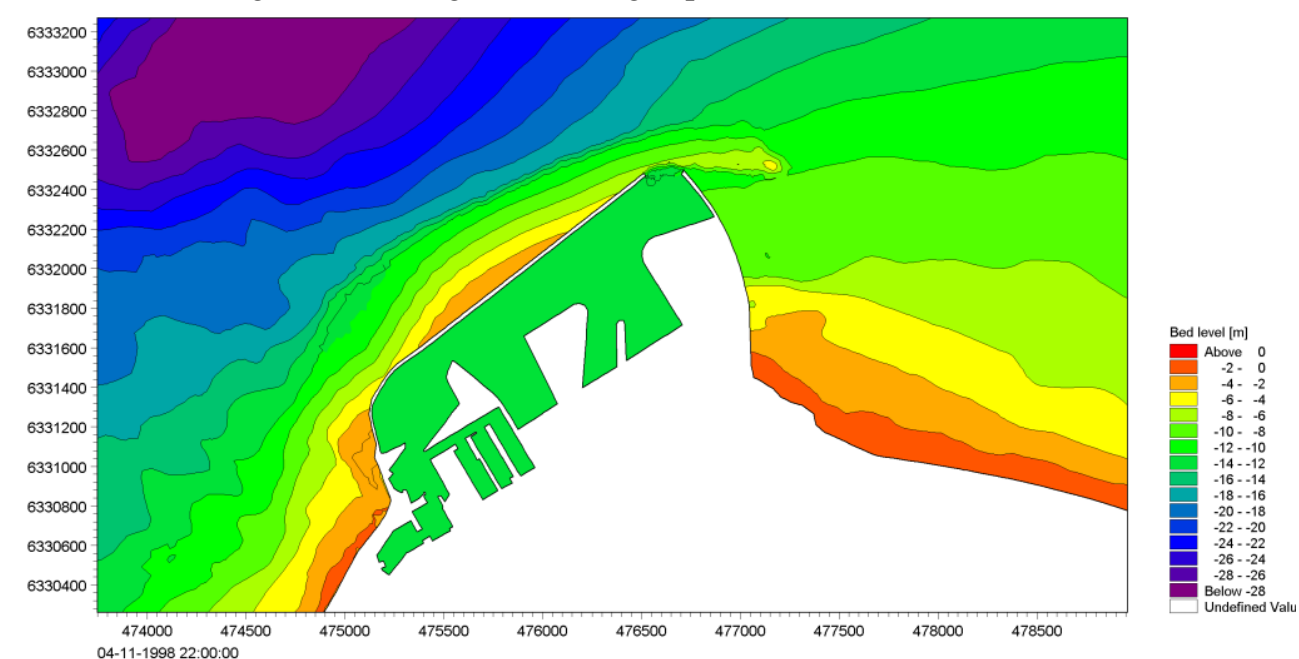

Figure 8. Example of instantaneous bed configuration in simulation by the hybrid model. 


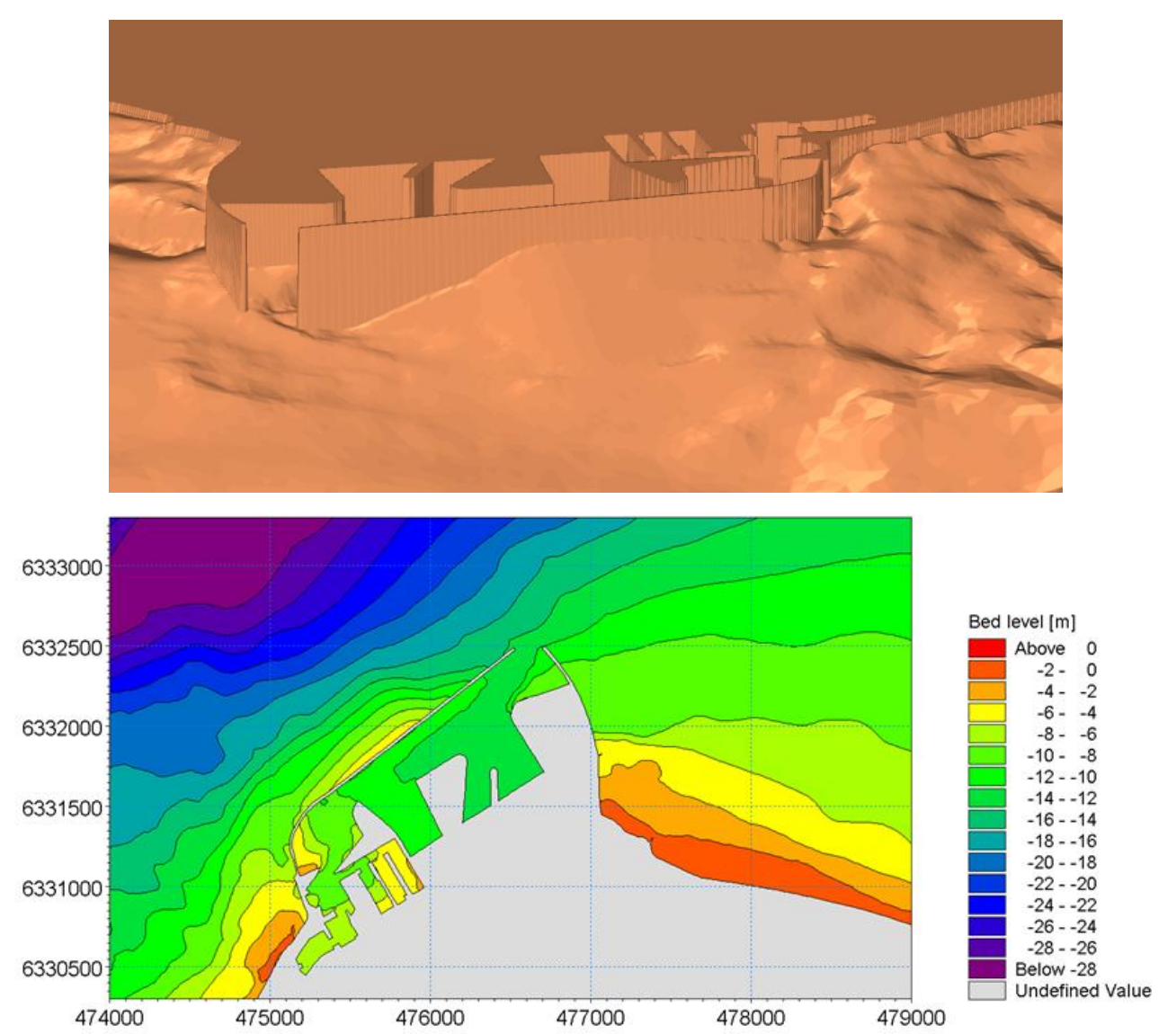

Figure 9. Bed configuration with a $1,000,000 \mathrm{~m}^{3}$ reservoir updrift of the harbour entrance.

It is seen that the water depth at the harbour mouth is only 8-9 $\mathrm{m}$, which means that a bypass solution without significant maintenance dredging is not realistic and a dredging strategy must be established, which allows for uninterrupted operation of the harbour even after severe storm events. This means that a reservoir has to be established updrift (west) of the harbour mouth that can absorb the sand deposited under normal conditions as well under a severe storm. The reservoir can be established by dredging along the main northern breakwater, maintaining the original water depth along a section immediately west of the harbour mouth. A reservoir solution has the advantage that the maintenance dredging can be carried out in larger infrequent operations that can be planned well in advance. The effective volume of the reservoir can be estimated as the difference between the equilibrium bathymetry and the bathymetry with the reservoir. Fig. 9 shows a configuration with a reservoir of $1,000,000 \mathrm{~m}^{3}$. 

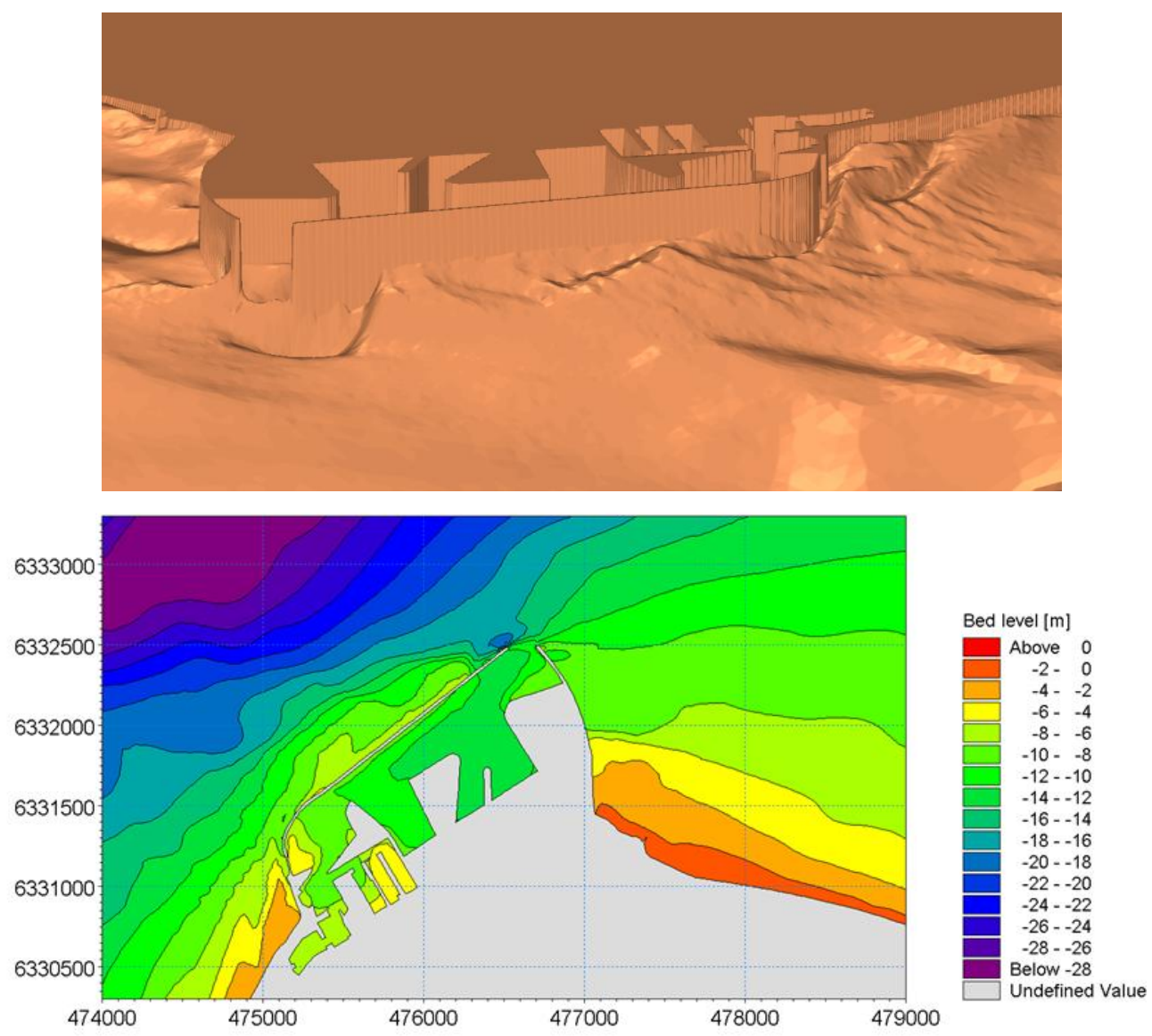

Figure 10. Morphological simulation of the bed configuration with the reservoir after a normal year of storm conditions followed by the extreme 2005 storm.

The behaviour of this reservoir has been studied by a series of morphological simulations, where the evolution of the reservoir in time is simulated under a series of storms corresponding to a normal year followed by an extreme event found as the most severe storm (January 07-09 2005) during the 32 years simulated by the regional models. Fig. 10 shows the bathymetry with the reservoir following the normal year and the subsequent extreme storm. The sand is deposited in the reservoir before reducing the navigation depth in the harbour entrance. According to the simulations there is a transport past the harbour mouth of approximately $20 \%$ of the transport towards the reservoir even at the large depth of $12.5 \mathrm{~m}$, which means that the expected maintenance dredging is approximately $80 \%$ of the sediment transport coming to the harbour from the coast south of it or approximately $400,000 \mathrm{~m}^{3}$. The deposition in the reservoir can be expected to vary considerably from year to year because of changes in the number and severity of storms.

\section{IMPACT ON THE SURROUNDING COASTLINES}

A change in the sedimentation and dredging at Hanstholm Harbour may affect the surrounding coastlines. Analysis of the transport conditions around the present and the future harbour shows that the sand transport past the harbour in west-going direction is negligible and that the transport conditions around the west part of the harbour is practically unchanged. It is therefore concluded that the harbour expansion will have no impact on the updrift coast southwest of it. A change in the bypass conditions could, however, affect the downdrift coast east of the harbour. The investigations have therefore concentrated on the coast to the east, between the harbour and Lild Strand at the next promontory $25 \mathrm{~km}$ to the east.

\section{Sand budget}

The Sand budget for the coastal stretch east of Hanstholm has been analysed on the basis of historic maps and survey data. The coastlines have been extracted from topographic maps from the years, 2004, 1978, 1960, 1918, 1883 and 1780, cf. Fig. 11 The earliest survey (1780) has not been 
considered but the remaining coastlines are expected to be quite reliable. The coastlines show a significant erosion in Vigsø Bay 7-12 km east of the harbour. The erosion is expected to be due to an imbalance between the amount of sand coming past the harbour and the transport capacity along the coast east of the harbour. The fact that the erosion takes place $7 \mathrm{~km}$ away while the position of the coastline immediately east of the harbour is practically constant is attributed to the presence of hard limestone in the coastal profile on the first $7 \mathrm{~km}$. The erosion has therefore set in as soon as loose sand has been encountered. The presence of the limestone in the coastal profiles can be observed directly, and is also indicated in geological maps, and is apparent from the profiles that have been surveyed on a regular basis since 1969 by the Danish Coastal Authority.
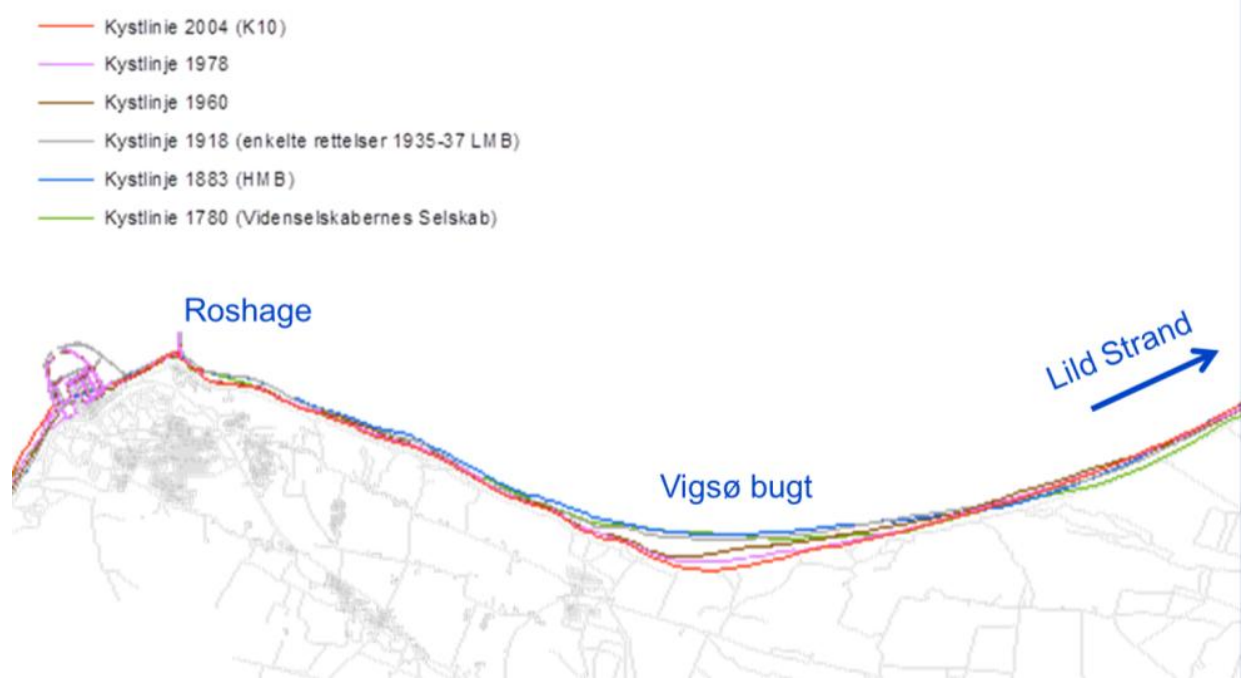

Figure 11. Coastlines extracted from geographical maps, courtesy Inst. of Geography and Geology, University of Copenhagen.

From the coastlines and the 25 detailed profiles surveyed by the Danish Coastal Authority (DCA) the variation in the littoral drift along the coast can be determined. The absolute magnitude of the transport depends on the supply of sand passing the harbour, which has been put to $400,000 \mathrm{~m}^{3} / \mathrm{yr}$. The resulting sediment budget is shown in Fig 12.

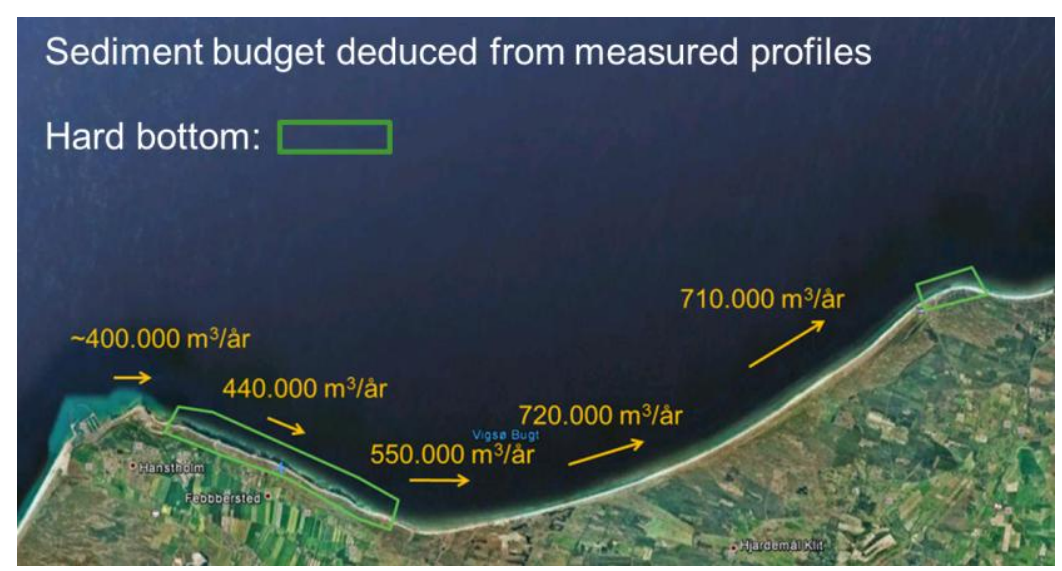

Figure 12. Sediment budget for the coastline east of Hanstholm based on Coastlines and profiles surveyed by DCA, Background: Google Earth.

\section{Littoral drift calculations}

The wave conditions obtained from 32 years simulated by the regional wave model were extracted in four nearshore points, the wave roses illustrating the variability along the coastline are given in, Fig 13. The littoral transport capacity was calculated by the model LITDRIFT, which for a given incoming wave condition calculates the wave parameters, the wave driven current and the longshore sediment 
transport over the coastal profile, the longshore transport is integrated over the profile to give the resulting longshore transport. The net longshore transport calculated for representative profiles and the four wave roses is also shown in Fig 13. It can be seen that the results are in close agreement with the transport derived from survey data except immediately east of the harbour, where the transport will be reduced because of exposed hard limestone beds.

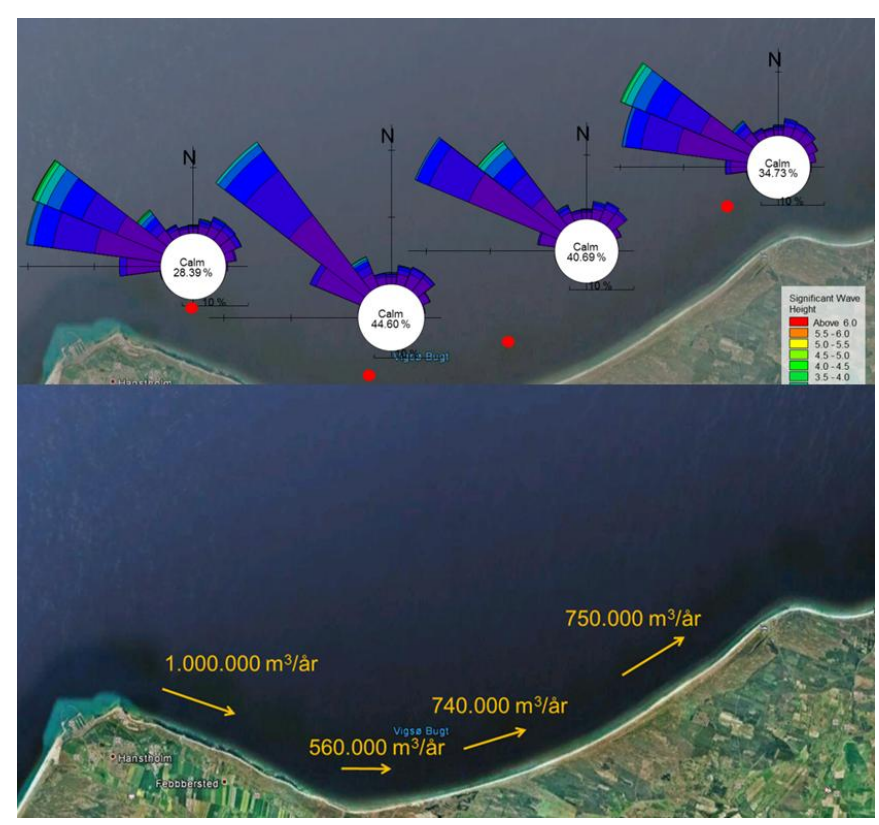

Figure 13. Top: Nearshore wave roses at the coast east of Hanstholm. Bottom: Littoral drift capacity calculated by the LITDRIFT model.

\section{Shoreline evolution}

The shoreline evolution was simulated by the model LITLINE, which describes the changing coastline by a one-line model combined with the LITDRIFT littoral drift model. The model is thus consistent with LITDRIFT, and the transport is similar except for a modification made for very oblique wave incidence in order to avoid instabilities in the simulation of the shoreline evolution, which gives a minor increase in the calculated littoral transport rates.

A modification has been introduced in the LITLINE model to account for the hard limestone beds, which protect against coastal erosion even though there is a sediment deficit compared to the transport capacity. The hard bed is introduced as a curve in the model, where the transport goes towards zero as the coastline approaches this erosion resistant line, similar to a starving bed formulation, Fig 14.

Figure 15 shows the simulated shoreline evolution from 1960 to 2004. It is seen that the model reproduces the historical evolution quite well, and that the erosion resistant hard bottom gives a realistic description of the progression of the erosion in Vigsø Bay. Fig. 16 shows a comparison between the calculated and the measured change in the shoreline from 1960 to 2004. It is seen that the model reproduces the coastline movement quite well, with a deviation far to the east near Lild Strand which is later seen to be outside the area of influence from a change in the sedimentation and dredging practise for the Port of Hanstholm. 

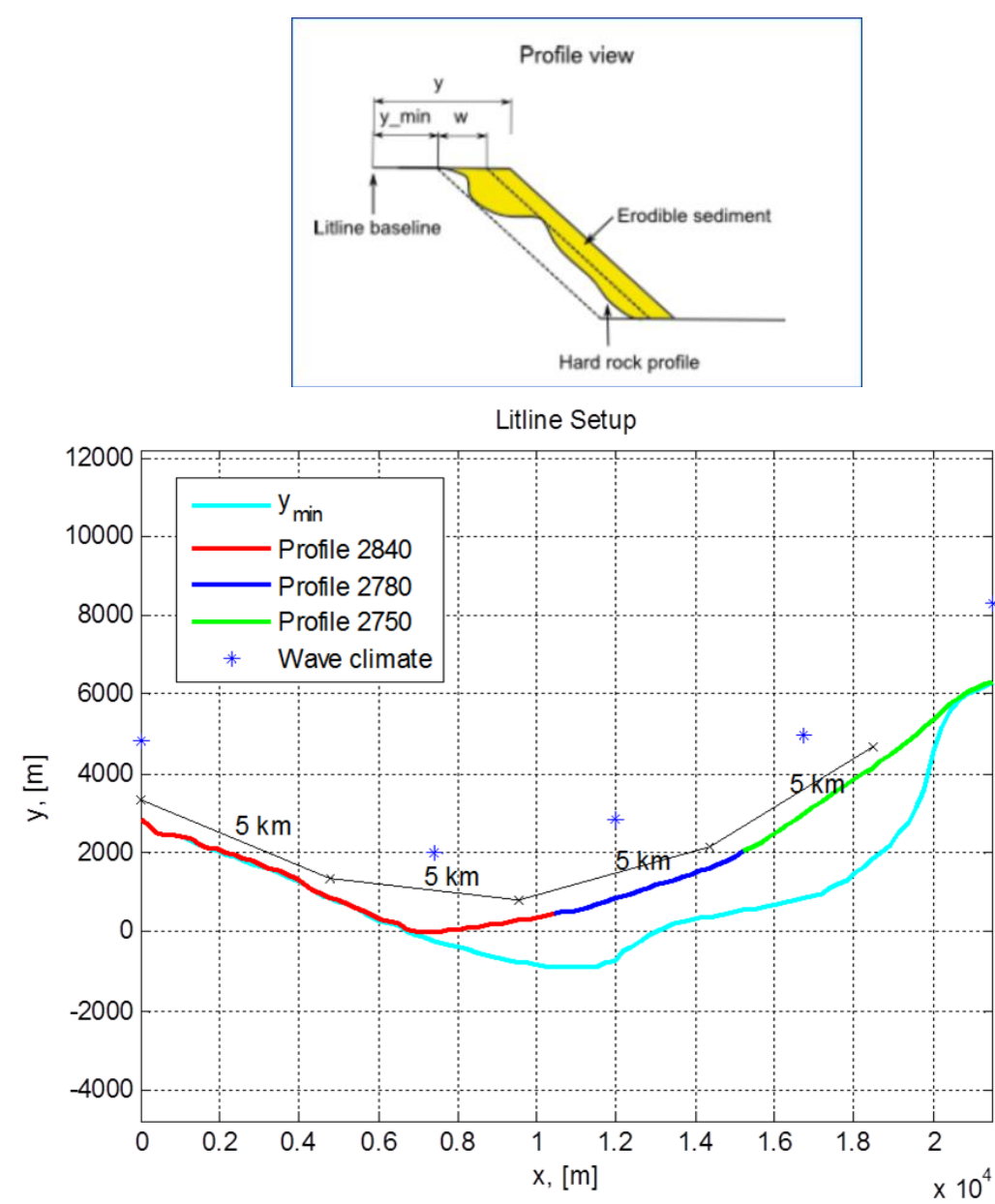

Figure 14. Top: The principle in the hard bottom formulation. The littoral drift is gradually reduced to zero as the coastline recedes from position $Y_{\min }+W$ to $Y_{\min }$. Bottom: The set-up of the LITLINE model by use of three coastal profiles, five wave climates and the position of the hard erosion-resistant bed. 


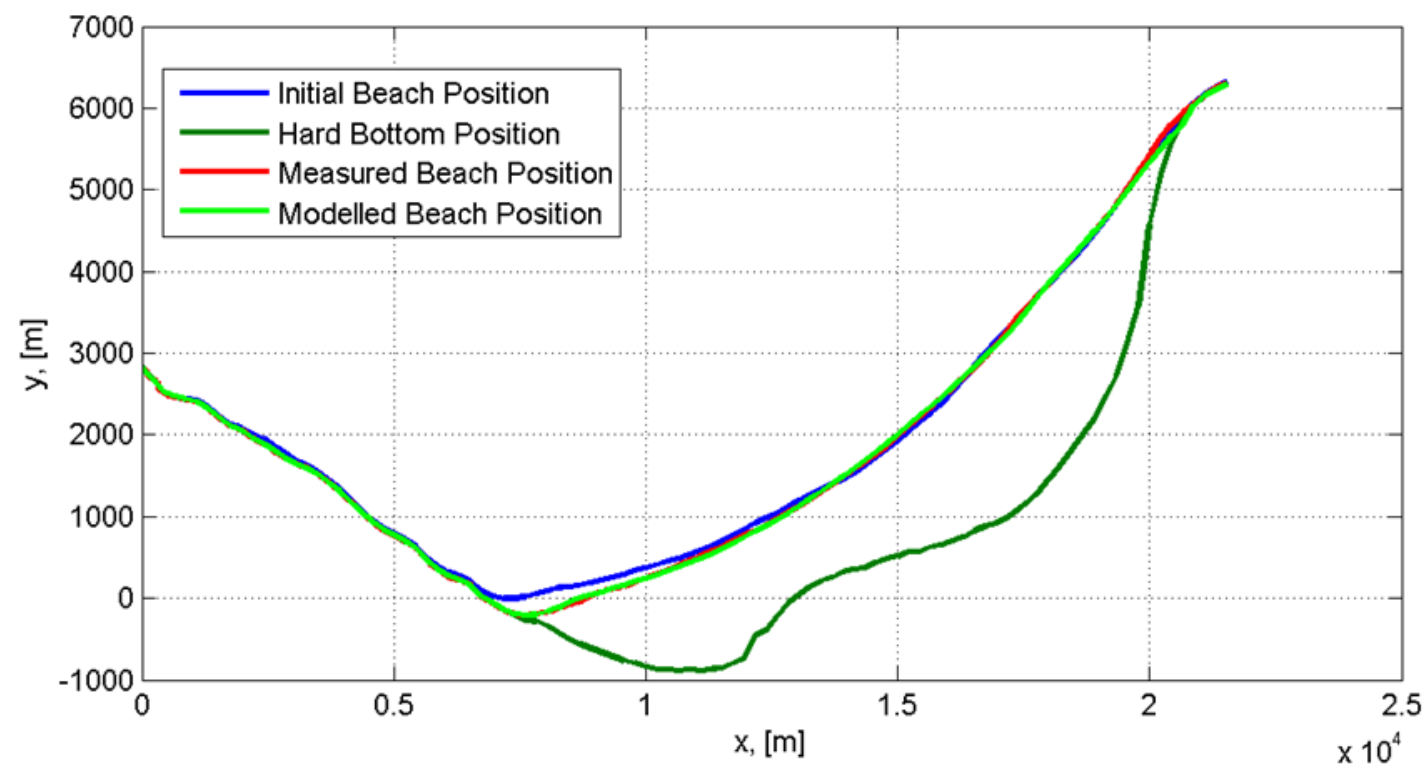

Figure 15. The measure and the simulated evolution in the shoreline from 1960 to 2004.

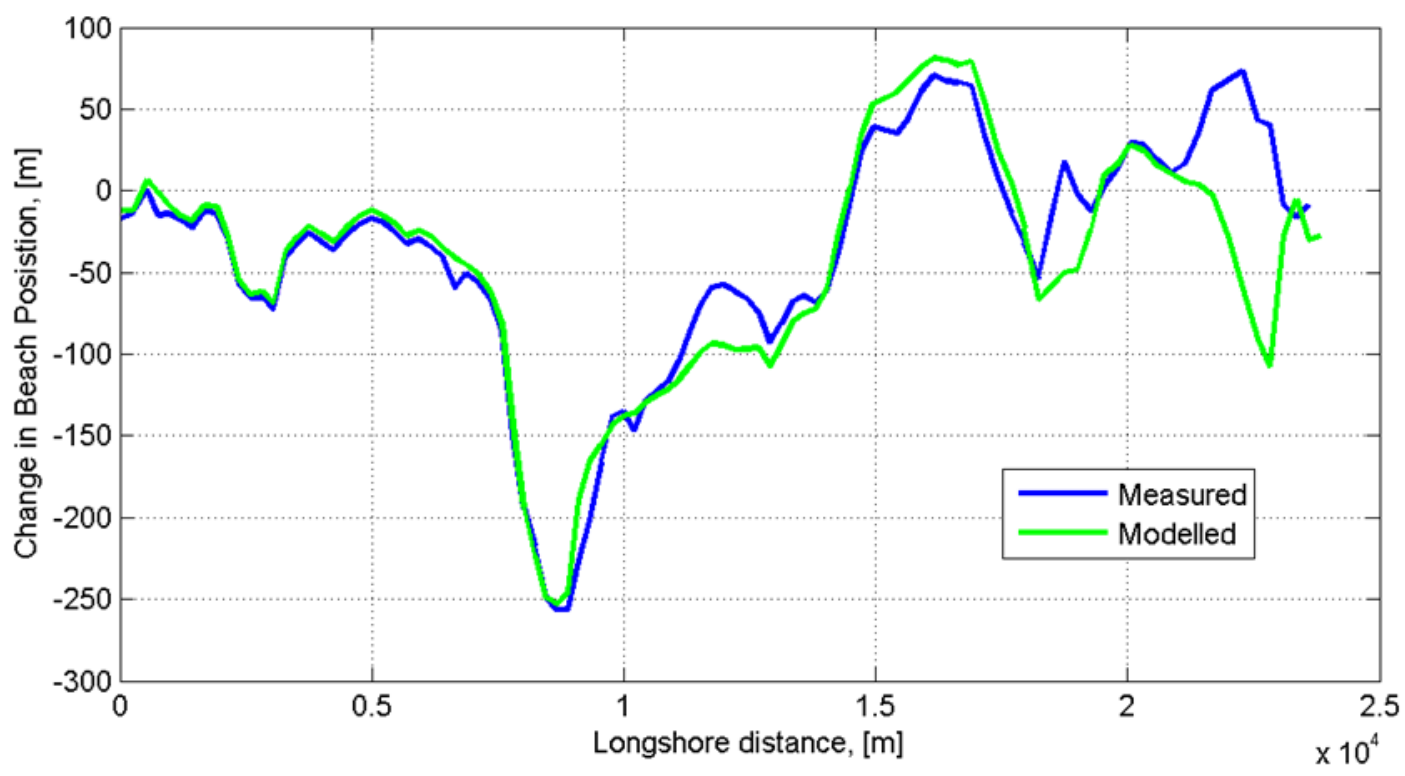

Figure 16. The change in the shoreline position from 1960 to 2004, measured and modelled.

The future evolution for the next 44 years was simulated for a number of different scenarios. A baseline case with unchanged conditions (full bypass of sediment) and four simulations with a bypass of sediment corresponding to $75 \%, 50 \%, 25 \%$ and $0 \%$ of the present rate. It is seen, Fig. 17, that for the baseline case the erosive trend is continued, while the erosion is aggravated as the bypass of sediment past the harbour is reduced. Possible remedial action against an increase in the erosion is to introduce artificial bypass by placing the material dredged in front of the harbour close to the downdrift shoreline. 

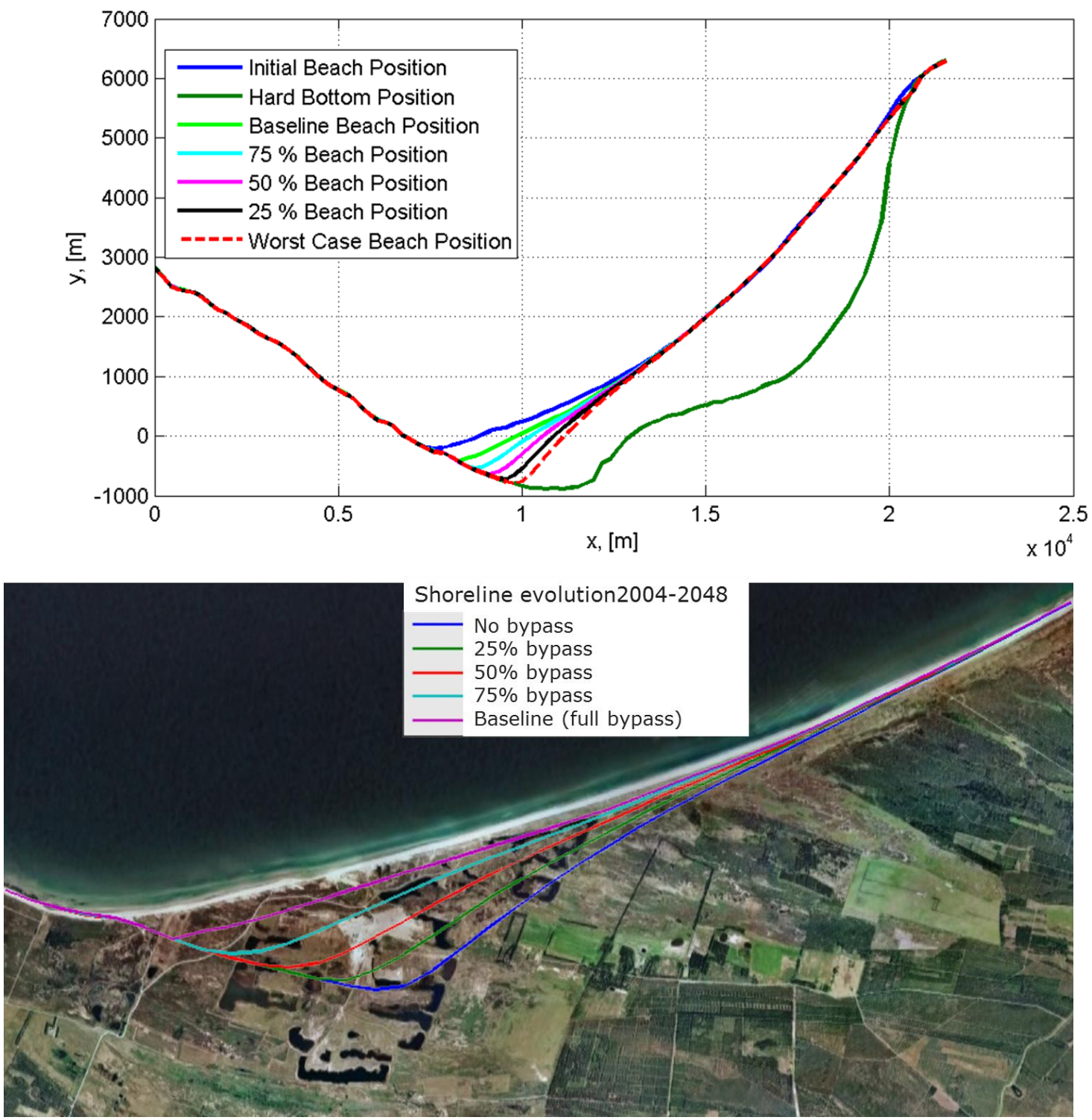

Figure 17. Top: The simulated shoreline evolution from 2004 to 2048 for different bypass conditions. Bottom: detail with background from Google Earth $\AA^{\text {. }}$.

\section{ACKNOWLEDGMENTS}

The hybrid morphological model has been developed under the project: Danish Coasts and Climate Adaptation - flooding risk and coastal protection (COADAPT), financed by the Danish Council for Strategic Research (DSF), project no. 09-066869.

\section{REFERENCES}

Brøker, I., J. Zyserman, E.Ø. Madsen, K. Mangor and J. Jensen. 2007. Morphological modelling: A tool for optimization of coastal structures. J. of Coastal Res., Vol. 23(5), pp. 1148-1158.

Kristensen, S.E., N. Drønen, R. Deigaard, J. Fredsøe. 2013. Hybrid morphological modelling of shoreline response to a detached breakwater. Coastal Engineering, Vol. 71, pp. 13-27 (in Press).

Kristensen, S.E., R. Deigaard, M. Taaning, J. Fredsøe, N. Drønen and J.H. Jensen. 2010. Long term morphological modelling. In: Smith, J.M. and P. Lynett (Eds.), Proceedings of the 32nd International Conference on Coastal Engineering, vol. 1. ASCE, Shanghai, China. URL , http://journals.tdl.org/ICCE/article/view/1260. 
Sørensen, T., J. Fredsøe, and P.R. Jakobsen. 1996. History of Coastal Engineering in Denmark, pp. 103-141. In: History and Heritage of Coastal Engineering, Edited by Nick Kraus, ASCE, New York, $603 \mathrm{pp}$. 